\title{
Designing a Curriculum to Meet the Needs of Caregivers of Patients who had a Cerebral Vascular Accident (CVA) Living in Local Communities in Zimbabwe
}

\author{
Farayi Kaseke \\ University of Zimbabwe, farayi.kaseke@gmail.com \\ Amelia Challender \\ University of Colorado, Denver, amelia.challender@ucdenver.edu \\ Mary Jane Rapport \\ University of Colorado, Anschutz Medical Campus, maryjane.rapport@ucdenver.edu
}

Follow this and additional works at: https://nsuworks.nova.edu/ijahsp

Part of the Medicine and Health Sciences Commons

\section{Recommended Citation}

Kaseke F, Challender A, Rapport M. Designing a Curriculum to Meet the Needs of Caregivers of Patients who had a Cerebral Vascular Accident (CVA) Living in Local Communities in Zimbabwe. The Internet Journal of Allied Health Sciences and Practice. 2016 Jan 01;14(1), Article 6.

This Manuscript is brought to you for free and open access by the College of Health Care Sciences at NSUWorks. It has been accepted for inclusion in Internet Journal of Allied Health Sciences and Practice by an authorized editor of NSUWorks. For more information, please contact nsuworks@nova.edu. 


\title{
Designing a Curriculum to Meet the Needs of Caregivers of Patients who had a Cerebral Vascular Accident (CVA) Living in Local Communities in Zimbabwe
}

\begin{abstract}
Background: Cerebral Vascular Accident (CVA), or stroke, has become an epidemic in Zimbabwe with the incidence rising significantly over the past two decades. Most patients in Zimbabwe who have had a CVA are initially admitted into a hospital for the acute phase of care and later discharged back to the community and into the care of their family. Although caregivers are forced to suddenly take on a critical role in the daily care and rehabilitation of the person who has had a stroke and continues to have disabilities, there is little to prepare someone for these responsibilities at the time the patient returns home or even in the weeks and months following. Caregiver support, which can be extended through education in how to assist the patient with daily routines and mobility, has been shown to improve the quality of life of patients and caregivers. The need to develop a standardized curriculum for use with family and other primary caregivers was identified by faculty involved in health professions education at the University of Zimbabwe College of Health Sciences. The primary purpose of the curriculum was to meet the needs of caregivers responsible for individuals who had a CVA and returned to live in their local communities in Zimbabwe. Purpose: Thus, the purpose of this paper is to describe the process of curriculum development, from needs assessment through curricular design and evaluation, as an opportunity to demonstrate how physical therapists and other allied health professionals can address community need through curriculum design. Methods: A questionnaire was developed to ascertain curricular content from the people who had a stroke and designated caregivers. Results: Intended outcomes of the curriculum included evidence of (1) decreased caregiver burden among caregivers responsible for people who have survived a stroke and returned to live in their local communities in Zimbabwe; and (2) increased function and health related quality of life of the patient who has had a stroke and of their caregiver over a period of one year. Conclusion: Although this curriculum was designed specifically to meet the needs of caregivers in Zimbabwe, the process for curriculum development and the curriculum content can be adapted in many other countries and for other rehabilitation related situations.
\end{abstract}

\section{Author Bio(s)}

- Farayi Kaseke, BScHPT, MScPT, MScSM, Lecturer, Physiotherapy Program, Department of Rehabilitation, College of Health Sciences, University of Zimbabwe, Harara, Zimbabwe.

- Amelia Challender, MA, Senior Evaluation Specialist, The Evaluation Center School of Education and Human Development, University of Colorado, Denver, CO, US.

- Mary Jane Rapport, PT, DPT, PhD, FAPTA, Professor, School of Medicine, Physical Therapy Program, University of Colorado, Anschutz Medical Campus, Aurora, Colorado, US. 


\title{
TIAHSP \\ The Internet Joutnal of Allied Health Sciences and Practice
}

Dedicated to allied health professional practice and education

Vol. 14 No. 1 ISSN 1540-580X

\section{Designing a Curriculum to Meet the Needs of Caregivers of Patients who had a Cerebral Vascular Accident (CVA) Living in Local Communities in Zimbabwe}

\author{
Farayi Kaseke, BScHPT, MScPT, MScSM ${ }^{1}$ \\ Amelia Challender, $\mathrm{MA}^{2}$ \\ Mary Jane Rapport, PT, DPT, PhD, FAPTA 3 \\ 1. University of Zimbabwe \\ 2. University of Colorado, Denver \\ 3. University of Colorado, Anschutz Medical Campus \\ Zimbabwe / United States
}

\begin{abstract}
Cerebral Vascular Accident (CVA), or stroke, has become an epidemic in Zimbabwe with the incidence rising significantly over the past two decades. Most patients in Zimbabwe who have had a CVA are initially admitted into a hospital for the acute phase of care and later discharged back to the community and into the care of their family. Although caregivers are forced to suddenly take on a critical role in the daily care and rehabilitation of the person who has had a stroke and continues to have disabilities, there is little to prepare someone for these responsibilities at the time the patient returns home or even in the weeks and months following. Caregiver support, which can be extended through education in how to assist the patient with daily routines and mobility, has been shown to improve the quality of life of patients and caregivers. The need to develop a standardized curriculum for use with family and other primary caregivers was identified by faculty involved in health professions education at the University Of Zimbabwe College Of Health Sciences. The primary purpose of the curriculum was to meet the needs of caregivers responsible for individuals who had a CVA and returned to live in their local communities in Zimbabwe. Purpose: Thus, the purpose of this paper is to describe the process of curriculum development, from needs assessment through curricular design and evaluation, as an opportunity to demonstrate how physical therapists and other allied health professionals can address community need through curriculum design. Methods: A questionnaire was developed to ascertain curricular content from the people who had a stroke and designated caregivers. Results: Intended outcomes of the curriculum included evidence of (1) decreased caregiver burden among caregivers responsible for people who have survived a stroke and returned to live in their local communities in Zimbabwe; and (2) increased function and health related quality of life of the patient who has had a stroke and of their caregiver over a period of one year. Conclusion: Although this curriculum was designed specifically to meet the needs of caregivers in Zimbabwe, the process for curriculum development and the curriculum content can be adapted in many other countries and for other rehabilitation related situations.
\end{abstract}

\section{INTRODUCTION}

Cerebral Vascular Accident (CVA), or stroke, has become an epidemic in Zimbabwe with the incidence rising significantly over the past two decades. In the capital city of Harare alone, the rate has gone from 31/100,000 to 57/100,000 in the decade from 19861997 and then increased further to $107 / 100000$ by $2011 .^{1-3}$ As such, Zimbabwe now ranks $85^{\text {th }}$ in the world in terms of incidence of stroke with an age adjusted death rate of 107.75 per 100,000.1-3 Most patients in Zimbabwe who have had a CVA, heretofore referred to as stroke, are initially admitted into a hospital for the acute phase of care. But when stable, these individuals with disabilities are discharged back to the community and into the care of their family on whom they rely heavily for physical, emotional, and psychological support. ${ }^{4}$ Rehabilitation starts in the acute phase during initial hospitalization, but during this period, the rehabilitation personnel rarely meet with the caregivers of these patients who have had a stroke to discuss ongoing progress and to make plans prior to discharge. A primary reason for this absence of meetings and communications is likely that family visitation and rehabilitation treatment occurs at different times without attempts to coordinate meetings. Thus, in most cases, the only time 
the caregiver is involved in stroke rehabilitation is upon discharge when the caregivers are given a home program to ensure continuity of care with outpatient follow up visits to a specialized stroke clinic. However, financial constraints and distances from rural communities to the centralized health centers in Zimbabwe where the outpatient services are located may limit follow up and ongoing support for these caregivers.

A successful patient discharge hinges on the premise that family members and close relatives will provide necessary care, but in reality, relatives are suddenly thrust into a caregiver role upon patient discharge, for which they are ill-prepared, leaving them in a predicament around providing adequate and supportive care. ${ }^{5}$ Since most of the recovery following a stroke takes place at home over many months, patient dependence creates a significant burden on the caregivers who find themselves assuming new roles on top of existing responsibilities in their daily lives. In fact, the result of the additional burden may lead to a breakdown in the caregivers' health resulting in an erosion and eventual disintegration of the support provided to the patient who had a stroke by the caregiver. $4,5,7$ The success of family caregiver support may determine the final outcome of patients who have had a stroke because the ability of the family caregivers to adjust to the patient's disability has implications for the patient's quality of life and participation within their family and community. ${ }^{7}$

Following discharge from the hospital, patients may continue to be seen in an outpatient status at the rehabilitation clinics where caregivers are usually encouraged to attend therapy sessions and may get informal instruction on facilitation of transfers, mobility, and activities of daily living tasks. Unfortunately, the primary caregiver is not always the person who brings the patient for rehabilitation services, and any education provided during the clinic visit may not be passed on to the caregiver, or may be shared incorrectly or partially by this second hand source. In addition, coordination of care and case management services are limited to the patient's acute inpatient stay in the hospital and are not designed to provide assistance during any extended outpatient episode of care, including the outpatient visits to a rehabilitation clinic.

Providing caregivers with support through education that will better enable them to assist the patient with daily routines, and mobility has been shown to improve the quality of life of patient and caregivers. A study by Singh et al on caregivers of people living with HIV (PLWHA) in South Africa found that caregivers who received support had a lower caregiver burden and were more than twice as willing to care for another person living with HIV in the future. ${ }^{8}$ Kalra et al also found that caregivers who received training reported significantly improved quality of life, burden of care, and mood outcomes at both 3 and 12 months compared to caregivers who had no training. ${ }^{7}$ Kalra et al concluded that training caregivers in basic skills of moving and handling and facilitation of activities of daily living reduces the burden of care and improves the quality of life in patients and caregivers. Even more promising is the Cochrane review by Legg et al that identified a structured training program for caregivers of patients returning home after stroke as an intervention with promise of reducing caregiver burden while enhancing their well-being. ${ }^{9}$ Only recently has the London Stroke Carers Training Course been published and made more available, and even then, access to materials and tools can be substantially limited in other countries. ${ }^{10}$

The absence of a documented curriculum available for training caregivers of patients who have had a stroke and returned to live in local communities in Zimbabwe was evident; hence, faculty involved in health professions education at the University of Zimbabwe identified the need to develop a standardized curriculum for use with family and other primary caregivers prior to patient discharge from acute care. The process of developing a curriculum to train caregivers of survivors of stroke was guided by the Kern model, which includes six steps: Problem Identification and General Needs Assessment, Targeted Needs Assessment, Goals and Objectives, Educational Strategies, Implementation, and Evaluation and Feedback. ${ }^{11}$ After initial problem identification by health professions faculty, a general and targeted needs assessment was conducted to confirm the need for a curriculum and to determine the specific needs of caregivers of people who have had a stroke. Next, the results of the needs assessment were used to develop goals and objectives to guide the curriculum. Next, educational strategies to address these goals and objectives were selected, and a plan to evaluate the program was created. Finally, the program was implemented and evaluated, with evaluation driving continuous program improvement.

The primary purpose of the curriculum was to meet the needs of caregivers responsible for individuals who had a stroke and returned to live in their local communities in Zimbabwe. Intended outcomes of the curriculum included evidence of (1) decreased caregiver burden among caregivers responsible for people who have survived a stroke and returned to live in their local communities in Zimbabwe; and (2) increased function and health related quality of life of the patient who has had a stroke over a period of one year. Thus, the purpose of this paper is to describe the process of curriculum development, from needs assessment through curricular design and evaluation, as an opportunity to demonstrate how physical therapists and other allied health professionals can address community needs through curriculum design. Secondarily, the curriculum is shared here as an outcome of the process. Although this curriculum was designed specifically to meet the needs of caregivers in Zimbabwe, the process for curriculum development and the curriculum content can be adapted in many other countries and for other rehabilitation situations.

(C) The Internet Journal of Allied Health Sciences and Practice, 2016 


\section{METHODS}

To confirm the need for a curriculum beyond what was derived from the knowledge and experience of physical therapy faculty at the University of Zimbabwe, a general and targeted needs assessment was carried out based on the Kern model of curriculum development. ${ }^{11}$ Ethical approval to conduct the study was granted by the Joint Parirenyatwa Hospital and University of Zimbabwe College of Health Sciences Research Ethics Committee after clinical directors at the central hospitals granted permission for the study. A data management plan was followed to ensure data were stored safely and confidentially. Specifically, raw data were deidentified, and the files were stored in a safe, locked place that only the principal investigator had access to. De-identified electronic data were stored on a password-protected computer and backed up on a password-protected Dropbox account.

A questionnaire was developed to ascertain curricular content from the intended stakeholder groups (see description of data collection instruments below). Questionnaires were distributed to people who had a stroke and people who were designated caregivers. Questionnaires were completed by 53 people who had survived a stroke and 56 people who served as caregivers to a person who had survived a stroke. The completed questionnaires were manually entered into Microsoft Excel, and descriptive data analysis was conducted using statistical analysis software (Statistical Package for Social Science version 16.0).

\section{Sample Population}

The sample population was chosen using a descriptive cross-sectional design. From May to July 2012, the study team recruited participants meeting inclusion criteria from all patients attending outpatient physiotherapy and occupational therapy within rehabilitation departments at three teaching hospitals in Zimbabwe: Harare, Parirenyatwa, and Chitungwiza.

During the three-month sampling period, rehabilitation patients who met inclusion criteria were recruited to participate in the study. To be eligible for participation, patients had to be adults 18 and older who had received a clinical diagnosis of stroke at least three months prior and had been treated by a physiotherapist at least five times. Individuals were excluded from the study if they had functional limitations before having a stroke or had additional neurological diagnoses. Patients were also excluded if they did not have sufficient cognitive and communication abilities to understand and complete the questionnaire.

At the time of recruitment, participants completed an informed consent process. Among 74 patients who had a stroke receiving services during the three-month period and who met inclusion criteria, 53 consented to participate in the study and completed a questionnaire. The demographics of the participants are described in Table 1.

Table 1: Socio-demographic Data of People who Survived a Stroke

\begin{tabular}{|l|l|l|l|}
\hline \multirow{4}{*}{ Age } & & $\begin{array}{l}\text { Frequency } \\
(\mathbf{n}=\mathbf{5 3})\end{array}$ & $\begin{array}{l}\text { Percentage } \\
(\%)\end{array}$ \\
\hline \multirow{4}{*}{ Gender } & 18-44 years & 10 & 18.9 \\
\cline { 2 - 4 } & 45-65 years & 14 & 26.4 \\
\cline { 2 - 4 } & 65+ years & 29 & 54.7 \\
\hline \multirow{3}{*}{ Number of strokes } & Male & 22 & 41.5 \\
\cline { 2 - 4 } & Female & 31 & 58.5 \\
\cline { 2 - 4 } & One & 42 & 79.2 \\
\cline { 2 - 4 } & Two & 10 & 18.9 \\
\cline { 2 - 4 } & Three or more & 1 & 1.9 \\
\hline
\end{tabular}

Caregivers of these participants were also recruited for participation if they had attended at least five of the participants' physiotherapy appointments. While it has been noted that caregivers were often uninvolved with patient's appointments, this criteria for inclusion was felt to be important to gather information from caregivers who were able to identify gaps in knowledge or skills that could benefit their ability as a caretaker. Caregivers were defined as individuals living with and helping a person who had a stroke in activities of daily living and advocating on their behalf. ${ }^{7}$ In all, 56 caregivers consented to participate. The demographics of the caregiver participants are described in Table 2. 
Table 2: Socio-demographic Data of Caregivers

\begin{tabular}{|l|l|l|l|}
\hline & & $\begin{array}{l}\text { Frequency } \\
(\mathbf{n}=\mathbf{5 6})\end{array}$ & $\begin{array}{l}\text { Percentage } \\
(\mathbf{\%})\end{array}$ \\
\hline \multirow{4}{*}{ Age } & $18-44$ years & 36 & 64.3 \\
\cline { 2 - 4 } & $45-65$ years & 11 & 19.6 \\
\cline { 2 - 4 } & $65+$ years & 9 & 16.1 \\
\hline \multirow{4}{*}{ Pender } & Male & 24 & 42.9 \\
\cline { 2 - 4 } & Female & 32 & 57.1 \\
\hline \multirow{5}{*}{ Period as caregiver } & $<3$ months & 22 & 39.3 \\
\cline { 2 - 4 } & $>3-6$ months & 9 & 16.1 \\
\cline { 2 - 4 } & $>6-9$ months & 11 & 19.6 \\
\cline { 2 - 4 } & $>9-12$ months & 5 & 8.9 \\
\cline { 2 - 4 } & $>12$ months & 9 & 16.1 \\
\hline
\end{tabular}

Note a: The overlap in time periods intentionally allowed patients and caregivers the opportunity to select the most accurate time frame to best represent the changes in daily care and responsibilities as the result of stroke.

\section{Data Collection Instruments}

Separate questionnaires were developed for use with people who had a stroke and their caregivers. The questionnaires were designed to understand the needs and gaps in knowledge among both people who had strokes and their caregivers. These instruments included questions drawn from three existing instruments. Questions related to needs were derived from the Southampton Needs Assessment Questionnaire (SNAQ), an instrument designed for use in cross-sectional surveys conducted with individuals with disabilities. ${ }^{12}$ Research by Bakas et al provided the basis for questions related to needs, concerns, strategies, and advice for caregivers of people who had a stroke during the first 6 months after discharge from hospital. ${ }^{13}$ To understand satisfaction with existing services for other evaluation purposes (separate from this study), the instrument also included questions about perceptions of physiotherapy services, derived from the Verona Service Satisfaction Scale-European version. ${ }^{14}$ The two resulting questionnaires combined modified, abbreviated versions of the three instruments into a single form, incorporating only questions relevant to the participant groups in this study (see Appendix A for the questionnaires).

The questionnaires were translated into Shona, the native language of most residents of the Harare area, and piloted at Chitungwiza Central Hospital with three survivors of stroke and three caregivers. Based on the results of the pilot administration, open-ended questions were revised to improve clarity. Following consent, the questionnaires were administered before or after physiotherapy appointments within the hospital's department of rehabilitation. Depending on the literacy of study participants, the instrument was orally administered by a research assistant or completed independently on paper by participants.

\section{RESULTS}

Generally, caregivers' responses to questionnaires confirmed the need for a curriculum. Forty-three caregivers $(76.8 \%)$ reported a need for information about the warning signs of stroke, $38(67.9 \%)$ reported a need for understanding the risk factors of stroke, and $42(75 \%)$ reported a need to understand the condition of stroke itself. Caregivers also reported a need for assistance in caring for the patient and providing the necessary level of support to assist with mobility and activities of daily living.

Thirty-five caregivers (62.5\%) reported needing help with using public transportation with the patient and thirty-two (57.1\%) reported needing assistance with patient self-care activities like bathing, dressing and escorting the patient to the bathroom. Twenty-seven $(48.2 \%)$ reported needing assistance with mobilizing the patient, and $21(37.5 \%)$ reported a need for home adaptations. The caregivers also identified that they needed help on how to communicate with the patient $(60.7 \%)$, understand and cope with patient's changed personality (51.8\%), and address cognitive issues in the patient such as forgetfulness (39.3\%). The majority of patients identified their need for assistance with activities of daily living like bathing, dressing and using the bathroom (66\%) and need for assistance with mobility (60.4\%). The patients recognized their dependence on caregivers for this assistance.

\section{Curriculum Development}

Overall, the findings of the needs assessment reinforced the need for a curriclum. Following Kern's model of curricular development, the curriculum's goals and objectives were informed by responses to the questionnaires; other rehabilitation personnel also informed the process.

Table 3 was developed as a Logic Model to assist with the development of a curriculum and evaluation plan. The Logic Model also

(c) The Internet Journal of Allied Health Sciences and Practice, 2016 
served to specifically address the resources necessary for curriculum implementation. Beyond addressing the needs assessment, the overall impact of the curriculum was focused on creating an optimal holistic health care system in Zimbabwe prepared to reduce the impact of stroke on caregivers and as well as the people who have survived a stroke.

\section{Table 3: Logic Model}

\begin{tabular}{|c|c|c|c|c|}
\hline Resources & Outputs & $\begin{array}{c}\text { Immediate Program } \\
\text { Outcomes }\end{array}$ & $\begin{array}{c}\text { Intermediate } \\
\text { Program Outcomes }\end{array}$ & Impact \\
\hline $\begin{array}{l}\text {-People who } \\
\text { have had a } \\
\text { stroke } \\
\text {-Caregivers of } \\
\text { people who } \\
\text { have had a } \\
\text { stroke } \\
\text {-Training } \\
\text { materials } \\
\text {-Locations } \\
\text { where training } \\
\text { will be held } \\
\text {-Support from } \\
\text { communities of } \\
\text { interest }\end{array}$ & $\begin{array}{l}\text { - Number of caregivers } \\
\text { enrolled } \\
\text { - Number of caregivers } \\
\text { trained } \\
\text { - Number of drop outs } \\
\text { - Number of caregivers } \\
\text { who develop } \\
\text { competencies in } \\
\text { caring for individuals } \\
\text { after stroke } \\
\text { - Number of caregivers } \\
\text { who are satisfied with } \\
\text { the training program } \\
\text { - Number of caregivers } \\
\text { confident to care for } \\
\text { individuals who have } \\
\text { had a stroke after } \\
\text { training }\end{array}$ & $\begin{array}{l}\text {-All caregivers of individuals } \\
\text { who have had a stroke are } \\
\text { knowledgeable, compassionate, } \\
\text { and dedicated in their care } \\
\text {-Caregivers demonstrate } \\
\text { competencies in the following } \\
\text { areas: } \\
\text { - Explaining the causes and } \\
\text { symptoms of stroke } \\
\text { - Explain how to manage } \\
\text { people who have had a } \\
\text { stroke and carry out } \\
\text { infection control in the } \\
\text { home } \\
\text { - Explaining how to } \\
\text { physically manage and lift } \\
\text { a patient with stroke } \\
\text { - Can assist patients who } \\
\text { have had a stroke with } \\
\text { mobility and activities of } \\
\text { daily living without } \\
\text { - Can identify and use } \\
\text { resources and services to } \\
\text { address their own psycho- } \\
\text { emotional needs } \\
\text {-Caregivers have confidence } \\
\text { and a positive attitude in } \\
\text { addressing the primary and } \\
\text { secondary problems } \\
\text { encountered by people who } \\
\text { have had astroke }\end{array}$ & $\begin{array}{l}\text {-People who have had } \\
\text { a stroke with } \\
\text { caregivers who } \\
\text { participated in the } \\
\text { training have } \\
\text { improved home based } \\
\text { support, leading to } \\
\text { better health. }\end{array}$ & $\begin{array}{l}\text { Outcomes and } \\
\text { prognosis for } \\
\text { individuals who } \\
\text { have survived a } \\
\text { stroke in } \\
\text { Zimbabwe is } \\
\text { improved and } \\
\text { the burden on } \\
\text { caregivers is } \\
\text { reduced. }\end{array}$ \\
\hline \multicolumn{5}{|c|}{$\begin{array}{l}\text { Underlying Assumptions: } \\
\text { - } \quad \text { The training program is fully implemented with fidelity to the established written goals and objectives } \\
\text { - } \quad \text { Government policies and resources are supportive of the curriculum and training for caregivers } \\
\text { - }\end{array}$} \\
\hline
\end{tabular}

The goals and objectives of the curriculum were developed around cognitive, psychomotor and affective domains of competency. The overall goal of the curriculum was to improve health outcomes of people who have had a stroke by increasing caregivers' foundational knowledge of stroke as a disease process and improving their skills related to providing daily care to a person who has had a stroke by providing training and resources. It was believed that a two-day course would be able to include sufficient content to meet the goal. Several objectives were constructed around meeting the goal. Table 4 provides more detailed description of the goals and objectives and how each would be addressed within the curriculum. 
Table 4: Goals and Objectives of the Curriculum

\begin{tabular}{|c|c|c|c|c|}
\hline \multicolumn{5}{|c|}{$\begin{array}{l}\text { Goals: } \\
\text { Caregivers of stroke survivors will be knowledgeable about stroke as a condition, co-morbidities and daily management } \\
\text { of the stroke patient }\end{array}$} \\
\hline Specific Learning Objectives & $\begin{array}{c}\text { Competency } \\
\text { Domain }\end{array}$ & $\begin{array}{l}\text { Teaching } \\
\text { Methods }\end{array}$ & $\begin{array}{c}\text { Resources } \\
\text { Needed }\end{array}$ & $\begin{array}{l}\text { Assessment } \\
\text { Method }\end{array}$ \\
\hline $\begin{array}{l}\text { 1. By the end of the first session/day, the } \\
\text { participants should be knowledgeable } \\
\text { about the common causes and } \\
\text { symptoms of stroke as well as problems } \\
\text { faced in caring for people who have } \\
\text { survived a stroke. }\end{array}$ & Cognitive & $\begin{array}{l}\text { Lecture, } \\
\text { Discussion, } \\
\text { Videos }\end{array}$ & $\begin{array}{l}\text { Lecture } \\
\text { notes, } \\
\text { Pamphlets, } \\
\text { Participants }\end{array}$ & $\begin{array}{l}\text { Oral } \\
\text { discussion, } \\
\text { Feedback and } \\
\text { reflection }\end{array}$ \\
\hline $\begin{array}{l}\text { 2. By the end of the course, participants } \\
\text { should be knowledgeable about the } \\
\text { management of patients who have had a } \\
\text { stroke and be able to carry out infection } \\
\text { control in the home. }\end{array}$ & Cognitive & $\begin{array}{l}\text { Lectures, } \\
\text { Discussion }\end{array}$ & & \\
\hline $\begin{array}{l}\text { 3. By the end of the course, participants } \\
\text { should be able to assist patients who } \\
\text { have had a stroke with mobility and } \\
\text { activities of daily living without additional } \\
\text { support from the trainer. }\end{array}$ & Psychomotor & $\begin{array}{l}\text { Demonstration, } \\
\text { Discussion, } \\
\text { Role play }\end{array}$ & $\begin{array}{l}\text { Stroke } \\
\text { patients }\end{array}$ & $\begin{array}{l}\text { Practical } \\
\text { demonstration } \\
\text { Direct } \\
\text { observation }\end{array}$ \\
\hline $\begin{array}{l}\text { 4. By the end of the course, participants } \\
\text { should have a working knowledge of } \\
\text { resources and services to address } \\
\text { psycho-emotional needs (dealing with } \\
\text { stress and bereavement) and be able to } \\
\text { describe how to create support groups. }\end{array}$ & Affective & $\begin{array}{l}\text { Discussion, } \\
\text { Presentations }\end{array}$ & & $\begin{array}{l}\text { Practical } \\
\text { demonstration, } \\
\text { Oral } \\
\text { discussion, } \\
\text { Feedback and } \\
\text { reflection }\end{array}$ \\
\hline
\end{tabular}

\section{Syllabus}

The caregiver training was designed as a two- to three-day training course, or workshop that can be delivered by any appropirately trained health care personnel. The primary design was for two days; however, a third day could be added as necessary or upon request.

The syllabus for the curriculum included an introduction and theoretical discussion of simple anatomy of the brain and neurological control of the body functions. Information on the condition and presentation of stroke, physical changes, causes, complications and risk factors, and related diseases were also included. The syllabus also provided content designed to address some of the functional implications and practical aspects of stroke including the effects of excessive traction on the affected shoulder, maintaining range of motion, positioning, turning, moving the patient into sitting, standing, and assisting the patient with walking. Skills that were intended to be taught to caregivers included dressing, toileting, lifting, feeding, and communicating with the patient.

Each day included approximately 2 hours of theory and 3 hours of practical content delivered across an 8 hour span of time. During this period, time for breaks, lunch, discussion, and other support and networking opportunities would also be incorporated. Table 5 includes a sample list of course content and topics covered throughout the training. 
Table 5: Content in Curriculum

\begin{tabular}{|c|c|}
\hline Topic & Notes To Assist With Topic Development \\
\hline Stroke as a disease & $\begin{array}{l}\text { What is stroke? What are the causes of stroke? How does stroke } \\
\text { present? How is the diagnosis made? What is the prognosis? }\end{array}$ \\
\hline Identification & $\begin{array}{l}\text { Use of appropriate evaluation procedures to assess psychological } \\
\text { and physical state of patients. Accurate identification of the patient's } \\
\text { immediate and potential problems. Identifying the most urgent } \\
\text { primary problems. }\end{array}$ \\
\hline Problems faced by patients & $\begin{array}{l}\text { These range from sudden change in body image, immobility, } \\
\text { dependence on others for activities of daily living, and care and } \\
\text { personality changes. Also includes fears of loss of self and income } \\
\text { and insecurities. }\end{array}$ \\
\hline Problems faced by caregivers & $\begin{array}{l}\text { Sudden changes from being thrust into caregiver role. Patient } \\
\text { dependent on caregiver. }\end{array}$ \\
\hline Complications and prevention of stroke & $\begin{array}{l}\text { Changes in motor and sensory problems. Secondary issues from } \\
\text { immobility in cardio-respiratory and musculoskeletal systems. Issues } \\
\text { with urinary system, particularly incontinence }\end{array}$ \\
\hline Progression time frames & $\begin{array}{l}\text { Changes in status from flaccidity to spasticity; immobility to mobility } \\
\text { and recovery of lost function. }\end{array}$ \\
\hline Co morbidities & $\begin{array}{l}\text { Additional disease that may be found in stroke patients such as HIV, } \\
\text { tuberculosis hypertension and diabetes mellitus. }\end{array}$ \\
\hline Infection control & $\begin{array}{l}\text { Use of gloves and disinfectants to minimize exposure to HIV and } \\
\text { other potential infections. }\end{array}$ \\
\hline Handling of stroke patients & $\begin{array}{l}\text { Handling and training for positioning, preventing shoulder-hand } \\
\text { syndrome and shoulder subluxations. }\end{array}$ \\
\hline Activities of daily living & $\begin{array}{l}\text { Teach feeding, bathing, toileting and alternatives to assist with } \\
\text { dressing and any other personal activities of daily living. }\end{array}$ \\
\hline Lifting and transfers & $\begin{array}{l}\text { Different methods of lifting stroke patients. Use of one man method } \\
\text { as well as methods for patients who are completely dependent. Help } \\
\text { with facilitation of mobility and transfers as well as correct application } \\
\text { of lifting and transferring techniques for safety reasons. }\end{array}$ \\
\hline Treatment & $\begin{array}{l}\text { Devising a plan of care for treatment that includes an appropriate } \\
\text { progression and post-discharge programme of management. } \\
\text { Recognition of contraindications and precautions for treatment, } \\
\text { delivery of effective treatment and progression based on regularly } \\
\text { scheduled evaluation of the patient's progress. }\end{array}$ \\
\hline Communication & $\begin{array}{l}\text { Tailored to the needs of each individual with identification and referral } \\
\text { to appropriate resource persons or sources within the hospital and } \\
\text { community. }\end{array}$ \\
\hline $\begin{array}{l}\text { Role of different departments and of the } \\
\text { community in patient care }\end{array}$ & $\begin{array}{l}\text { Establishment of appropriate relationships with the patient and other } \\
\text { caregivers and members of the health care team. }\end{array}$ \\
\hline
\end{tabular}

\section{Methods/ Strategies of Teaching}

The curriculum was intended to be delivered using a variety of teaching methods and strategies in order to best engage the learners in the content within the cognitive, affective, and psychomotor domains. This paper is not intended to expand upon reasons for, or execution of, various teaching methods, but several of these strategies are included in Table 3 . Some of the methods or strategies include:

- Use of lectures and discussions during the sessions to present theoretical information and more dense content

- Use of handouts with pictures to reinforce theory and provide reminders for psychomotor skills (eg, assistance to transfer)

- Use of practical demonstrations with patients who have had a stroke

- Use of feedback and reflection during and between sessions 


\section{Curriculum Evaluation}

The participants' performance was assessed by the course instructor on completion of the training program. Performance was measured to determine gains in knowledge and skills with the intent of improving their ability to care for a patient following a stroke. The specific tools that were used for this process have not yet been fully developed, but Table 6 identifies a list of competencies that have been considered as part of the expected learning process for the caregivers.

\section{Table 6: Caregivers are expected to:}
1) Identify problems that stroke patients may have
2) Assist with activity limitations (rolling, coming up from lying to sitting, coming up from sitting to standing, transfers from bed to chair, to floor, to wheelchair to toilet seat, etc.) and participation restrictions (socialization and work related activities) of the patients.
3) Identify adverse health/medical reactions or co-morbid conditions that may need referral for further management (development of pressure sores, elevated blood sugar and blood pressure).
4) Prevent secondary complications of immobility (pressure sores, contractures, muscle weakness and respiratory and urinary tract infections) by doing passive movements, and assisting with turning patients, sitting up, standing and walking patient.
5) Provide suggestions to address problems with incontinence.
6) Provide suggestions to address nutritional problems.
7) Assist with activities of daily living (bathing, dressing, feeding, or toileting).
8) Safely lift and move a patient (one man lift, two men lift and using draw sheets).
9) Check for adverse health reactions to mobility and transfers, such as hypotension.
10) Use infection control methods (wearing protective clothing, sterilizing equipment and use of sterilizing solutions).

There is also a process for evaluation of the curriculum developed around the following key evaluation questions:

- To what extent did the caregivers master the curricular objectives and thus improve in their ability to care for patients following a stroke?

- Were caregivers satisfied that the training was a good use of their time?

- Were caregivers knowledgeable about stroke and management of the patient with this condition after the training?

- To what extent did the trainers (instructors) follow the goals and objectives of the training (measure of fidelity)?

Evaluation methods included a survey with caregivers conducted two weeks after the training to evaluate course satisfaction and an assess mastery of course objectives. Physiotherapy departmental statistics will also be analyzed to determine any change in the need for health care services by patients who had a stroke when their caregivers had participated in training. These results are not yet available and analyzed but will be used for curriculum evaluation and revision of the curriculum and teaching methods.

\section{DISCUSSION AND CONCLUSION}

This curriculum was developed with the express intent of meeting the needs of caregivers who were thrust into the role of caring for a family member, friend, or community member who had a stroke. Rehabilitation healthcare providers, and more specifically physiotherapists, had identified that the caregivers were unprepared for this role. The additional burden of suddenly becoming a caregiver appeared to cause significant stress on both the caregivers and the patients who needed the additional assistance and care. Given these attributes, the limited resources in many areas of Zimbabwe, and the distances required for travel to appointments and to access services, the idea around developing a curriculum that would provide training became a priority. However, before proceeding with curriculum development, the primary author conducted a needs assessment to further identify and clarify the most relevant and important areas of focus for the caregivers and patients. This needs assessment served as the framework for the development of the curriculum, the syllabus and teaching methods and the evaluation plan.

The curriculum was designed around the areas of greatest need as identified in the needs assessment and included foundational knowledge and psychomotor skills for caregivers. Areas of knowledge addressed simple anatomy of the brain and neurological control of the body functions. Information on the condition and presentation of stroke, physical changes, causes, complications and risk factors, and related diseases were also included. Psychomotor skills taught to caregivers included dressing, toileting, lifting, feeding, and communicating with the patient. There was also intent to address some of the functional implications and practical aspects of stroke including excessive traction on the affected shoulder, maintaining range of motion, positioning, turning, moving the patient into sitting, standing, and assisting the patient with walking. While there was a curriculum evaluation plan, the project has not progressed to that point. Once the curriculum is implemented, reviewed and evaluated, then evaluation data can be used to make modifications necessary to better meet intended goals and outcomes.

(C) The Internet Journal of Allied Health Sciences and Practice, 2016 
Although the curriculum was specific to Zimbabwe, the Kern curriculum development model can be a useful process for other allied health curriculum development projects and for identification of content. In addition, this curriculum designed to support the roles and responsibilities of caregivers who serve individuals who have had a stroke can be modified for use in other countries and potentially for different, but similar, diagnoses or conditions where the patient needs ongoing assistance with activities of daily living and typical routines, along with mobility in the home and community settings. Clearly the situation in Zimbabwe is not entirely unique to other countries, particularly when resources or travel may be factors affecting patient care and service delivery.

\section{References}

1. Matenga J, Kitai I, Levy L. Strokes among black people in Harare, Zimbabwe: Results of computed tomography and associated risk factors. BMJ (Clin Res Ed.). 1986 Jun;292(6536):1649-51. [PMID 3087559]

2. Matenga J. Stroke incidence rates among black residents of Harare. A prospective community based study. S Afr Med J. 1997;87(5):606-9. [PMID 9254819]

3. World health rankings. Health profile: Zimbabwe. WHO, 2011. Available at: http://www.worldlifeexpectancy.com/countryhealth-profile/Zimbabwe Accessed June 19, 2015.

4. Han B, Haley WE. Family caregiving for patients with stroke: Review and analysis. Stroke. 1999;30(7):1478-85. [PMID 10390326]

5. Anderson C, Mhurchu CN, Rubenach S, Clark M, Spencer C, Winsor A. Home or hospital for stroke rehabilitation? Results of a randomized controlled trial: II: Cost minimization analysis at 6 months. Stroke. 2000;31(5):1032-7. [PMID 10797162]

6. Anderson CS, Linto J, Stewart-Wynne EG. A population-based assessment of the impact and burden of caregiving for longterm stroke survivors. Stroke. 1995;26(5):843-9. [PMID 7740578]

7. Kalra L, Evans A, Perez I, Melbourn A, Patel A, Knapp M, Donaldson N. Training carers of stroke patients: randomised controlled trial. B M J. 2004;328(7448):1099. [PMID 15130977]

8. Singh D, Chaudoir SR, Escobar MC, Kalichman S. Stigma, burden, social support, and willingness to care among cares of PLWHA in home-based care in South Africa. AIDS Care. 2011;23(7):839-45. [PMID 21400316]

9. Legg LA, Quinn TJ, Mahmood F, Weir CJ, Tierney J, Stott DJ, Smith LN, Langhorne P. Nonpharmacological interventions for caregivers of stroke survivors. Cochrane Database Syst Rev. 2011;5(10):CD008179. [PMID 21975778]

10. Forster A, Dickerson J, Melbourn A, Steadman J, Wittink M, Young J, Kalra L, Farrin A, TRACS trial collaboration. The development and implementation of the structured training programme for caregivers of inpatients after stroke (TRACS) intervention: the London Stroke Carers Training Course. Clin Rehabil. 2015;29(3):211-20. [PMID 25057000]

11. Kern DE, Thomas PA, Howard D, et al. Curriculum Development for Medical Education: A Six-step Approach. Baltimore (MD): Johns Hopkins University Press; 1998.

12. Kersten P, McLellan L, George S, Smith JA. The Southampton Needs Assessment Questionnaire (SNAQ): A valid tool for assessing the rehabilitation needs of disabled people. Clinl Rehabil. 2000;14(6):641-50. [PMID 11128740]

13. Bakas T, Austin JK, Okonkwo KF, Lewis RR, Chadwick L. Needs, concerns, strategies, and advice of stroke caregivers the first 6 months after discharge. J Neurosci Nurs. 2002;34(5):242-51. [PMID 12391740]

14. Ruggeri M, Lasalvia A, Dall'agnola R, van Wijngaarden B, Knudsen HC, Leese M, Gaite L, Tansella M. Development, internal consistency and reliability of the Verona Service Satisfaction Scale-European Version EPSILON Study 7. European Psychiatric Services: Inputs linked to outcome domains and needs. Br J Psychiatry Suppl. 2000;177(39):s41-8. [PMID 10945077] 


\section{STROKE PATIENT QUESTIONNAIRE}

\section{Appendix A: Questionnaires}

Please answer every question and as truthful as possible.

\section{Section A: Demographic data}

How old are you?

18- 44

45- 65

$65+$

What is your gender?

Male

Female

What is your marital status?

Married

Divorced/separate

Widowed

Single

What is your occupational status?

Employed

Unemployed

Self-employed

Retired

On sick leave

What is your education level?

Primary

Secondary

Tertiary

Where are you staying?

My own house

Lodging

Staying with relatives

Which mode of transport are you using?

Private car

Public transport 
How are you paying your bills?

\section{Cash}

Medical aid

Social welfare

Other

Please specify

Medical History.

When did you have the stroke?

3 months ago

6 months ago

1 year ago

More than 1 year ago

What time did you have the stroke?

During the night

During the day

How did the symptoms appear?

Were you aware of what was happening?

If no, after how long did you become aware?

Which side has been affected?

How many strokes have you had?

\section{Suddenly/fast}

Slowly

Yes

No

Less than 1 week

1 week

More than 2 weeks

Left

Right

Both

One

Two

Three + 
What is the length of time since you had a stroke?

Are you on any medication?

How long have you been seen by a physiotherapist?

How often are you seen?

Are you able to come to all appointments?

If no, why can you not come?

\section{3-6 months}

6-9 months

9-12 months

$12+$ month

No

Yes

Please specify

Less than 3 months

3-6 months

6-9 months

9-12 months

$12+$ months

Once a month

Once in two weeks

Once a week

More than once a week

Yes

No

Money problems

Transport problems

Physiotherapy does not help

Other

Please specify 
Designing a Curriculum to Meet the Needs of Caregivers of Patients who had a Cerebral Vascular Accident (CVA) Living in Local Communities

Who else is seeing you besides a physiotherapist?

Doctor

Occupational therapist

Psychologist

Speech therapist

Counselor

Spiritual healer

Traditional healer

Other

Please specify 


\section{Section B: Need for physiotherapy services}

Please answer truthfully by ticking the box with a statement that applies to your needs.

1. I need more information about:

a) The first signs of stroke.

b) Lifestyle changes after stroke like eating habits, stopping smoking

c) Risk factors of stroke like high blood pressure

d) Medications I am taking

e) My condition

f) How to manage specific problems like pain

g) Which health professionals to call for help and advice.

2. I need help with keeping socially active like going out with family and friends.

3. I need help with communicating with my caregiver so that we understand each other.

4. I need help with taking my medications on time.

5. I need help with doing the exercises I have been given.

6. I need help with learning how to walk, transfer to wheelchair

7. I need assistance with bathing, dressing and going to the bathroom.

8. I need assistance on how to get money for my health care bills.

9. I need help with going to different places when using public transport.

10. I need help finding someone to care for me when my usual caregiver is away.

11. I need help in finding the best way to ask family and friends to care for me.

12. I would like some changes to be made to the house so that I can move freely.

13. I need help with sexual issues.

14. I would like to be seen more often by the physiotherapist. 


\section{CAREGIVER QUESTIONNAIRE}

Please answer every question and as truthful as possible.

\section{Section A: Demographic data}

How old are you?

18- 44

45- 65

$65+$

What is your gender?

Male

Female

What is your marital status?

Married

Divorced/ separated

Widowed

Single

What is your occupation?

Employed

Unemployed

Self-employed

Retired

Stopped to take care of patient

What is your education level?

Primary

Secondary

Tertiary

What is your relationship to the patient?

Spouse

Child

Paid helper

Relative

Which mode of transport are you using?

Private car

Public transport 
How are you paying the patient's bills?

How long has the patient been seen by a physiotherapist?

How often is the patient seen?

Are you able to come for all appointments with the patient?

If no, why can you not come?

How long have you been caregiver to this patient?
Cash

Medical aid

Social welfare

Other

Please specify

Less than 3 months

3-6 months

6-9 months

9-12 months

$12+$ months

Once a month

Once in two weeks

Once a week

More than once a week

Yes

No

Money problems

Transport problems

Physiotherapy does not help

Other

Please specify

Less than 3 months

3-6 months

6-9 months

9-12 months

$12+$ months 
Designing a Curriculum to Meet the Needs of Caregivers of Patients who had a Cerebral Vascular Accident (CVA) Living in Local Communities

Who else is seeing you besides a physiotherapist?

Doctor

Occupational therapist

Psychologist

Speech therapist

Counselor

Spiritual healer

Traditional healer

Other

Please specify 


\section{Section B: Need for physiotherapy services.}

Please answer truthfully by ticking the box with a statement that applies to your situation.

1. I need more information about:

a) The warning signs of stroke.

b) Lifestyle changes like eating habits, stopping smoking

c) Risk factors of stroke like high blood pressure

d) Medications the patient is taking

e) The patient's condition

f) How to manage specific problems like pain

g) Which health professionals to call for advice.

2. I need help with keeping the patient socially active like going out with family and friends.

3. I need help with communicating with the patient so that we understand each other.

4. I need help with dealing with the patient's changed personality.

5. I need help with dealing with the patient's problems with thinking like forgetfulness.

6. I need help with getting the patient to take medications on time.

7. I need help getting the patient do the exercises we have been given.

8. I need help with teaching the patient how to walk, transfer to wheelchair.

9. I need assistance with bathing, dressing and escorting the patient to the bathroom.

10. I need help with going to different places with the patient when using public transport.

11. I need help finding someone to care for the patient when I am away.

12. I need help in finding the best way to ask family and friends to care for patient.

13. I would like some changes to be made to the house so that the patient can move more freely.

14. I need help in dealing with other things in my life like balancing work, care giving and caring for other Family members.

15. I would like for the patient to be seen more often by the physiotherapist.

16. I need help taking care of my own health.

17. I need help with keeping my social life going like getting out with family and friends and going to church. 